\title{
OBTENÇÃO DE BIOGÁS A PARTIR DE COMBINAÇÕES DE RESÍDUOS DE ARROZ E ESTERCO SUÍNO
}

\author{
J. P. SILVA ${ }^{1}$, K. H. BERWIG ${ }^{1}$, A. DETTMER ${ }^{1}$ \\ ${ }^{1}$ Universidade de Caxias do Sul, Departamento de Engenharia Química \\ E-mail para contato: jaynapessuto@hotmail.com
}

\begin{abstract}
RESUMO - O aumento da geração de resíduos industriais torna eminente o problema referente à destinação dos mesmos. Atualmente, a maioria é destinada para aterros industriais e os dejetos suínos para sistemas de armazenamento. A digestão anaeróbia pode ser uma alternativa viável ambiental e economicamente. Este trabalho avaliou a biodegradabilidade e a geração de biogás a partir da adição de diferentes inóculos (lodo de curtume e esterco suíno) ao substrato (resíduo de arroz). Os resíduos foram caracterizados através da concentração de carbono orgânico e nitrogênio Kjeldahl total antes e após os ensaios. As amostras foram mantidas a $35^{\circ} \mathrm{C}$ por 19 dias. A adição de lodo ao arroz apresentou melhor resultado na produção de biogás $(136,6 \mathrm{~mL} / \mathrm{g}$ de sólido). $\mathrm{O}$ arroz em meio a solução tampão gerou 97,84 mL/g de biogás, destaca-se a importância do pH para biodegradação. Conclui-se que a digestão anaeróbia é ambientalmente viável para o tratamento de resíduos, em condições controladas, converte resíduos em biogás.
\end{abstract}

\section{INTRODUÇÃO}

Com a expansão do mercado nacional e internacional as atividades agropecuárias e industriais aumentaram suas demandas gerando além do produto final, grandes quantidades de resíduos. Entre as atividades agropecuárias destaca-se a suinocultura e a pecuária, esta última é a principal fornecedora de matéria-prima para a indústria coureira. O esterco gerado na suinocultura, geralmente, é destinado em esterqueiras, podendo provocar contaminação de solo e água, forte odor e, liberação de metano para atmosfera.

A indústria coureira gera grande quantidade de efluente líquido em seu processo, sendo que o tratamento para este resíduo requer a aplicação de tecnologias avançadas e exige que, na etapa microbiológica, haja microrganismos com grande capacidade de adaptação a mudanças nas características do efluente, além de variações climáticas.

A agricultura também está em fase de crescimento no Brasil, tornando necessário o controle e tratamentos alternativos de doenças que ocorrem nas plantas. Os tratamentos que usam como agente de controle fungos e bactérias estão em destaque. $\mathrm{O}$ arroz parboilizado pode ser utilizado como meio de crescimento para fungos do gênero Trichoderma spp. Após o desenvolvimento dos fungos, o cereal utilizado torna-se um resíduo. Neste contexto a digestão anaeróbia é uma alternativa para o tratamento dos resíduos de esterco suíno, lodo de ETE de curtume e arroz, gerando energia renovável como produto. 
O processo de degradação por microrganismos anaeróbios acontece de forma espontânea gerando, como produto da transformação o biogás. O biogás gerado no processo de digestão anaeróbia é um combustível limpo e versátil quando comparado a outros combustíveis sólidos ou líquidos convencionais e, ainda apresenta vantagens como baixa exigência de energia para o processo de obtenção. Este pode ser utilizado na produção de calor e/ou vapor, eletricidade e refrigeração e, quando purificado pode ser utilizado como combustível de veículos (Thangamani et al., 2010; Kipper, 2013 e Pierobon, 2007).

A digestão anaeróbia pode ser divida em três fases principais: hidrólise, acidogênese e metanogênese (Molino et al.,2012). No primeiro estágio (hidrólise) as bactérias fermentativas convertem a matéria orgânica de complexo insolúvel (celulose) em moléculas solúveis. Esta etapa é importante na digestão anaeróbia, pois pode ser limitante na conversão do teor de resíduos orgânicos em metano.

No segundo estágio as bactérias acetogênicas convertem o produto da fase orgânica simples em ácidos, dióxido de carbono e hidrogênio, ocorrendo a produção de ácido acético, ácido butírico, ácido propinóico e etanol. Os produtos formados durante a acetogênese são devidos a diferentes microrganismos. A reação de acetogênese é expressa da seguinte forma:

$$
\mathrm{C}_{6} \mathrm{H}_{12} \mathrm{O}_{6} \longrightarrow 2 \mathrm{C}_{2} \mathrm{H}_{5} \mathrm{OH}+2 \mathrm{CO}_{2}
$$

No terceiro e último estágio o metano é produzido por bactérias formadoras de metano (metanogeneses) por dois meios: clivagem do ácido acético para gerar o dióxido de carbono e metano, ou por redução de dióxido de carbono na presença de hidrogênio. A produção de metano é maior a partir da redução de dióxido de carbono, porém o limite da concentração de hidrogênio no digestor pode resultar na reação do acetato como principal produtor de metano.

Ainda de acordo com Dhayalan et al. (2007), existem duas vias distintas, através da qual é produzido o metano, que são determinadas pelos tipos de bactérias metanogênicas. As bactérias metanogenese acetoclástica que, convertem o ácido acético em metano e dióxido de carbono. A segunda via envolve as bactérias metanogenese hidrogenotrófica, que utilizam o dióxido de carbono e hidrogênio para formar o metano e água, a ação destas bactérias metanogênicas é complexa para conseguir uma completa degradação, porque os seus substratos têm um efeito inibitório sobre as fases iniciais de degradação.

As reações metanogênicas podem ser expressas como:

$$
\mathrm{CH}_{3} \mathrm{COOH} \longrightarrow \mathrm{CH}_{4}+\mathrm{CO}_{2}
$$

$$
\begin{aligned}
& 2 \mathrm{C}_{2} \mathrm{H}_{5} \mathrm{OH}+\mathrm{CO}_{2} \longrightarrow \mathrm{CH}_{4}+2 \mathrm{CH}_{3} \mathrm{COOH} \\
& \mathrm{CO}_{2}+4 \mathrm{H}_{2} \longrightarrow \mathrm{CH}_{4}+2 \mathrm{H}_{2} \mathrm{O}
\end{aligned}
$$

Alguns fatores são importantes para o processo de biodegradação tais como temperatura, $\mathrm{pH}$, e a relação carbono e nitrogênio $(\mathrm{C} / \mathrm{N})$. Este último é o fator que melhor 
caracteriza o equilíbrio do substrato e o inóculo, pois sua variação está relacionada com a velocidade de degradação do resíduo, Andreoli (2011).

O objetivo deste trabalho é avaliar a produção de biogás a partir da degradação por microrganismos anaeróbios de dejetos suínos, lodo de estação de tratamento de efluentes de curtume e arroz parboilizado utilizado na produção de fungos.

\section{MATERIAIS E MÉTODOS}

\subsection{Materiais}

O resíduo de arroz (substrato) utilizado no cultivo do fungo Trichoderma spp foi fornecido pela Empresa Caxiense de Controle Biológico Ltda (ECCB) de Caxias do Sul, RS.O dejeto suíno (inóculo) foi coletado em propriedade particular do município de Ibirubá, RS. O resíduo de lodo de estação de tratamento de efluentes (ETE) de curtume (inóculo), foi disponibilizado pela empresa Peles Pampa, localizada no município de Portão, RS.

\subsection{Caracterização dos Resíduos}

Os resíduos, e suas combinações, utilizados nos experimentos foram caracterizados no início e no final do ensaio de digestão anaeróbia. Antes da biodigestão os resíduos foram caracterizados através da determinação da umidade, sólidos totais, Nitrogênio Kjeldahl Total (NTK), carbono orgânico nos resíduos de arroz, esterco suíno e lodo de estação de tratamento de efluentes (ETE) de curtume. Após a realização dos ensaios, as amostras foram caracterizadas quanto ao teor de carbono orgânico e NTK.

A determinação da porcentagem de umidade e teor de sólidos totais dos resíduos de arroz e esterco suíno foi realizada com base nas normas ASTM D3790 (2012) e ASTM E1756 (2008), respectivamente. A análise de NTK foi realizada conforme uma adaptação da norma (ASTM D2868-10) e, a determinação de carbono orgânico foi realizada através da metodologia de Tedesco e colaboradores (2005), de acordo com o Boletim Técnico $\mathrm{N}^{\circ} 5$.

\subsection{Ensaio de digestão anaeróbia e geração de biogás}

Os ensaios de biodegradação por microrganismos anaeróbios foram realizados dispondo as amostras de resíduos em frascos de vidro com volume de $100 \mathrm{~mL}$, vedados com tampa de borracha e lacre de alumínio.

Com o objetivo de manter a relação $\mathrm{C}: \mathrm{N}$ na proporção ideal para o ensaio de biodegradação foi considerada neste trabalho a relação $12: 1$, foram utilizados $0,3 \mathrm{~g}$ (base seca) do resíduo de arroz, 3 g (base seca) do esterco suíno.

O volume de lodo de curtume utilizado para o experimento foi determinado a partir do experimento de Covington et al. (2003) que, para manutenção do teor de sólidos entre o resíduo e o meio de degradação, estes utilizaram $25 \mathrm{~mL}$ de inóculo para 0,5 g de substrato. 
Assim, foram utilizados $15 \mathrm{~mL}$ de lodo de estação de tratamento de efluentes (ETE) para 0,3 $\mathrm{g}$ de arroz.

Utilizou-se solução tampão com pH em torno de 7,0 com o objetivo de estabilizar o $\mathrm{pH}$, de forma a auxiliar o processo de biodegradação realizada por microrganismos. O volume de tampão adicionado aos frascos foi de $3,33 \mathrm{~mL}$, visando manter o teor de sólidos totais em torno de $9 \%$.

Foram realizados ensaios "controle", nos quais se avaliaram a produção de gás de cada inóculo e do substrato isoladamente. Os frascos foram dispostos em um banho termostático à temperatura de $35^{\circ} \mathrm{C}$.

Os resíduos e suas misturas permaneceram em ensaio enquanto foi constatada a geração de biogás pelo processo de digestão por microrganismos anaeróbios, através de medições diárias. Após 19 dias (404 horas) em ensaio verificou-se que não havia mais geração de gás, e as amostras foram retiradas do ensaio e enviadas para realização de análises.

\subsection{Cálculo da concentração de carbono orgânico, nitrogênio e cromo das amostras}

A concentração de carbono orgânico, nitrogênio para as amostras de arroz e esterco suíno foi determinada para fins comparativos entre o início e o final do ensaio de digestão. A equação 1 demonstra o método utilizado para o cálculo das concentrações.

$C_{\theta_{i} a}=\frac{\left(C_{\theta_{i} a 1} \cdot m_{a, 1}\right)+\left(C_{\theta_{i} a 2} \cdot m_{a, 2}\right)}{m_{t}}$

Onde:

$\mathrm{C}_{\mathrm{e}, \mathrm{a} 1}=$ Concentração do elemento (Carbono, Nitrogênio) no substrato

$\mathrm{m}_{\mathrm{a}, 1}=$ Massa do substrato $(\mathrm{g})$

$\mathrm{C}_{\mathrm{e}, \mathrm{a} 2}=$ Concentração do elemento (Carbono, Nitrogênio e Cromo) no inóculo

$\mathrm{m}_{\mathrm{a}, 2}=$ Massa do resíduo inóculo $(\mathrm{g})$

$\mathrm{m}_{\mathrm{t}} \quad=$ Massa do total da amostra $(\mathrm{g})$

\subsection{Determinação do volume de gás produzido}

A verificação do volume de gás gerado foi realizada através do método volumétrico, que consiste no deslocamento de um fluido. No experimento, com o auxílio de uma proveta foi possível quantificar o volume de gás gerado, através do deslocamento da água e, para evitar a solubilização de $\mathrm{CO}_{2}$ foi utilizada solução com pH 2,0. A quantidade de água acumulada na proveta é considerada como a quantidade de volume de biogás gerado pela biodegradação dos resíduos contidos nos frascos de vidro.

\section{RESULTADOS E DISCUSSÃO}




\subsection{Caracterização das amostras}

Os resultados da caracterização das amostras quanto ao teor de carbono e nitrogênio estão apresentados na Tabela 1.

Tabela 1 - Concentrações de carbono orgânico e nitrogênio total nas amostras em base seca

\begin{tabular}{lcc}
\hline & Teor Carbono $(\%)(\mathrm{m} / \mathrm{m})$ & Teor de Nitrogênio $(\%)(\mathrm{m} / \mathrm{m})$ \\
\hline Arroz & 42,79 & 0,89 \\
Esterco Suíno & 41,16 & 2,41 \\
Lodo de ETE de curtume & 27,9 & 1,23 \\
\hline
\end{tabular}

Nota: ${ }^{2}$ - A relação utilizada para cálculo foi massa/volume $(\mathrm{m} / \mathrm{v})$

As concentrações de carbono orgânico e nitrogênio calculadas de acordo com a equação 1, nas amostras antes e depois do ensaio, bem como o teor de redução são apresentadas na Tabela 2. Destaca-se que para as amostras 4, 5 e 6 que apresentam a solução tampão, foi considerada a mesma concentração da amostra sem esta solução devido a não inferência da composição dos resíduos.

Tabela 2 - Concentrações de carbono orgânico e nitrogênio total nas amostras

\begin{tabular}{|c|c|c|c|c|c|c|c|}
\hline & & \multicolumn{3}{|c|}{ Carbono Orgânico } & \multicolumn{3}{|c|}{ Nitrogênio Total } \\
\hline Amostra & Composição & $\begin{array}{c}\text { Concentração } \\
\text { Inicial (\%) } \\
(\mathbf{m} / \mathbf{m})\end{array}$ & $\begin{array}{c}\text { Concentração } \\
\text { Final (\%) } \\
(\mathbf{m} / \mathbf{m})\end{array}$ & $\begin{array}{c}\text { Redução } \\
(\%)\end{array}$ & $\begin{array}{c}\text { Concentração } \\
\text { Inicial }(\%) \\
(\mathbf{m} / \mathbf{m})\end{array}$ & $\begin{array}{c}\text { Concentração } \\
\text { Final (\%) } \\
(\mathbf{m} / \mathbf{m})\end{array}$ & $\begin{array}{c}\text { Redução } \\
(\%) \\
(\mathbf{m} / \mathbf{m})\end{array}$ \\
\hline 1 & Arroz & 40,74 & 42,79 & -1 & 0,89 & 0,82 & 7,86 \\
\hline 2 & Esterco suíno & 41,16 & 42,37 & -1 & 2,41 & 1,68 & 30,29 \\
\hline 3 & $\begin{array}{l}\text { Arroz + esterco } \\
\text { suíno }\end{array}$ & 40,95 & 42,08 & -1 & 1,65 & 1,51 & 8,48 \\
\hline 4 & Arroz + tampão & 40,74 & 37,81 & 7,19 & 0,89 & 1,24 & -1 \\
\hline 5 & $\begin{array}{l}\text { Esterco suíno + } \\
\text { tampão }\end{array}$ & 41,16 & 42,07 & -1 & 2,41 & 1,37 & 43,15 \\
\hline 6 & $\begin{array}{l}\text { Arroz + esterco } \\
+ \text { tampão }\end{array}$ & 40,95 & 40,29 & 1,61 & 1,65 & -1 & -1 \\
\hline 7 & Arroz + lodo & 37,83 & 24,66 & 34,81 & 1,00 & -1 & -1 \\
\hline 19 & $\begin{array}{l}\text { Lodo de } \\
\text { curtume }^{2}\end{array}$ & 27,90 & 12,92 & 53,70 & 1,23 & 1,19 & 3,25 \\
\hline
\end{tabular}

Nota: ${ }^{1}$ Indisponibilidade de material para análise.

2 A relação utilizada para cálculo foi massa/volume $(\mathrm{m} / \mathrm{v})$

Através da análise de variância observa-se que ocorreu diminuição na concentração de carbono orgânico nas amostras que contem uma mistura de lodo de curtume e, em amostra que contém solução tampão, ou seja, as amostras 4, 6, 7 e 19. Comparando o resultado da amostra que contém a solução tampão com a amostra que contém em sua composição o lodo 
de curtume, a última apresentou maior redução neste teor de carbono. A solução tampão conforme Tawfic et al. (2009) é de extrema relevância para um processo eficaz de biodegradação e consequente geração de biogás.

A redução do teor de carbono orgânico está vinculada a biodegradação. Na realização das suas análises, Haroun el al. (2009) verificaram a redução do teor deste parâmetro no lodo de curtume em aproximadamente $25 \%$.

Nas amostras 1,2,3 e 5 verifica-se o aumento da concentração inicial, este aumento não esperado pode ser justificado pela diferença nos métodos de análise realizados.

Destaca-se que as amostras que continham esterco suíno tiveram redução não considerável de carbono orgânico, indicando que sua adição ao resíduo de arroz não propiciou melhoria no processo de biodegradação, sugerindo a existência de microrganismos ou outros compostos que podem ter inibido o processo de digestão anaeróbia. Porém, verifica-se a redução na concentração de nitrogênio nas amostras $1,2,3,5$ e 19, este resultado enfatiza a importância do controle do pH durante a digestão anaeróbia.

\subsection{Volume de gás medido}

O volume de biogás gerado durante o ensaio de biodegradação pode ser visualisado na Figura 1, que ilustra a geração de biogás acumulado, volume por unidade de massa de sólido $(\mathrm{mL} / \mathrm{g})$ em relação ao tempo de ensaio nas Condições Normais de Temperatura e Pressão (CNTP).

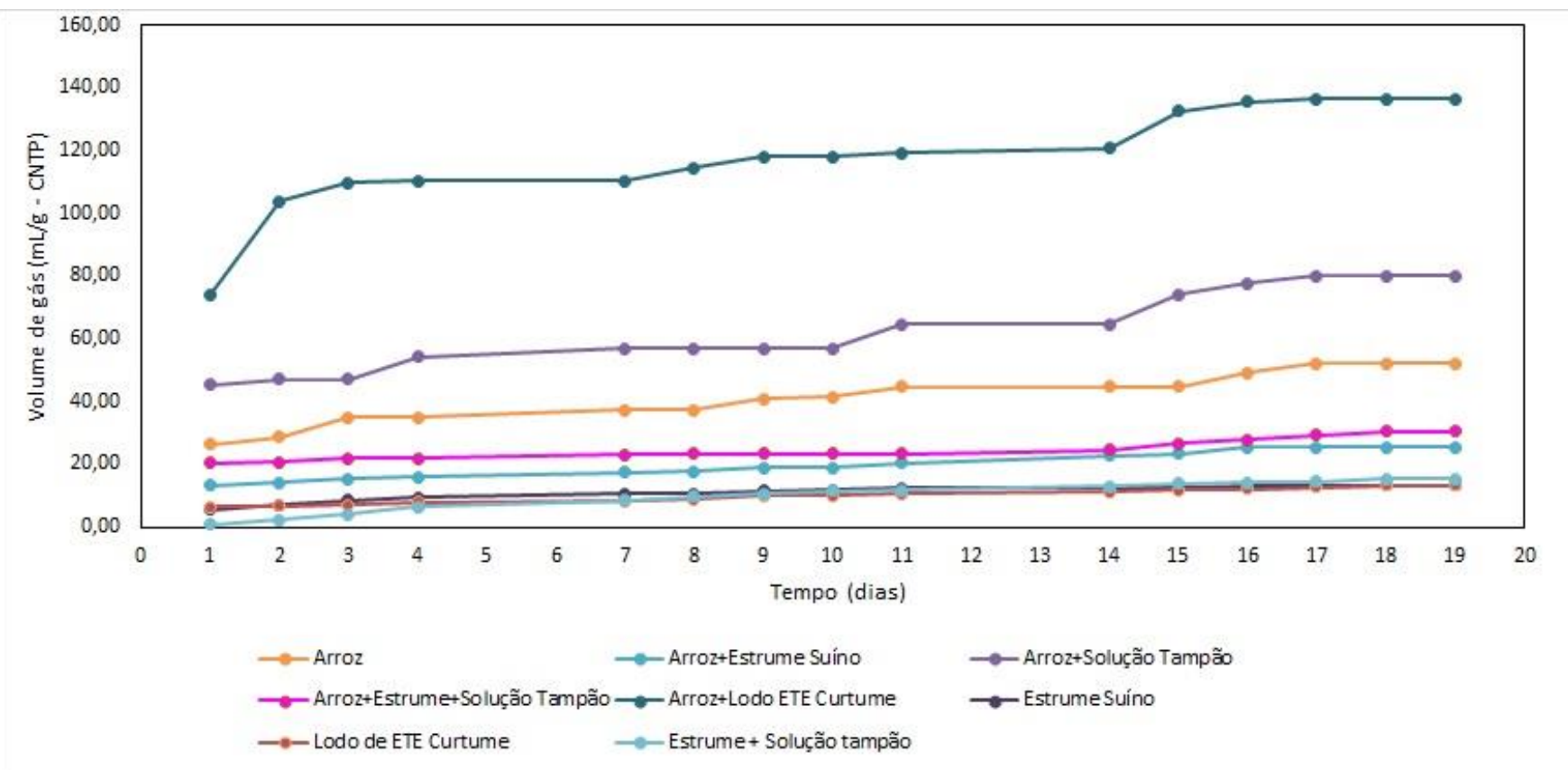

Figura 1 - Volume acumulado de biogás gerado na CNTP 
Analisando o gráfico da Figura 1, verifica-se que a amostra de lodo de curtume adicionada ao arroz teve maior geração de biogás quando comparada as outras amostras. Da mesma maneira, destaca-se através que o menor volume de gás gerado por massa de amostra foi a amostra de esterco suíno.

Verifica-se que as amostras que apresentaram adição de solução tampão tiveram um maior acúmulo de gás gerado durante o ensaio, quando comparadas as amostras sem adição de solução tampão. $\mathrm{O}$ arroz com solução tampão gerou 52,36\% a mais de biogás em comparação a amostra sem esta solução. Da mesma forma, o esterco com tampão gerou 89,04\% a mais de volume de gás em relação a amostra sem solução e, ainda, a amostra de arroz e esterco com solução tampão acumulou $87,52 \%$ de gás a mais que a amostra sem tampão.

Observa-se que o substrato (arroz) na presença do lodo de curtume apresentou o maior volume de gás gerado acumulado em comparação às outras amostras. Provavelmente, devido a concentração ideal de sólidos totais e a presença de microrganismos capazes de gerar biogás. Verifica-se ainda que os resultados de geração de biogás e a redução das concentrações de carbono e nitrogênio após o ensaio de biodegradação estão diretamente relacionadas, corroborando com os trabalhos de Raposo et al. (2011), Thamagani et al. (2010), Haroun el al. (2009), entre outros que mencionam a importância da manutenção de um meio com pH neutro, condições de umidade e teores de carbono e nitrogênio.

\section{CONCLUSÃO}

Após o ensaio de digestão anaeróbia, verificou-se que os teores de carbono e nitrogênio foram reduzidos, indicando dessa forma um efetivo processo de biodegradação, obtendo o biogás como produto.

As amostras que continham solução tampão apresentaram maior volume de biogás gerado, enfatizando a importância do controle do pH durante o processo de transformação de resíduos em energia renovável.

A adição do lodo de estação de tratamento de efluentes de curtume ao substrato produziu o maior volume de biogás, sendo este resultado justificado pelos microrganismos presentes neste inóculo, que auxiliaram o processo de digestão anaeróbia e consequentemente a produção de gás.

Desta forma, através dos resultados obtidos constata-se que a digestão anaeróbia é uma solução ambiental para o tratamento de resíduos e, em condições adequadas é fonte de energia renovável. 


\section{AGRADECIMENTOS}

À Fundação de Amparo à Pesquisa do Estado do Rio Grande do Sul (FAPERGS) pelo apoio financeiro cedido na forma de projeto de pesquisa para realização deste trabalho. A Universidade de Caxias do Sul pela estrutura física para realização dos ensaios.

\section{REFERÊNCIAS}

AMERICAN SOCIETY FOR TESTING AND MATERIALS.ASTM D 3790 - Standard Test Method for Volatile Matter (Moisture) of Leather by Oven Drying.Conshohocken, 2012.

AMERICAN SOCIETY FOR TESTING AND MATERIALS.ASTM E1756- Standard Test Method for Determination of Total Solids in Biomass.. Conshohocken, 2008.

AMERICAN SOCIETY FOR TESTING AND MATERIALS. ASTM D2868: Standard Test Method for Nitrogen Content (Kjeldahl) and Hide Substance Content of Leather. West Conshohocken: 2010.

ANDREOLI. C.V. Resíduo Sólido de Saneamento: Processamento, Reciclagem e Disposição Final, PROSAB, disponível em:〈www.finep.gov.br/prosab/livros/cleverson.pdf $>$. Acesso em: $23 / 04 / 2013$

COVINGTON, A.D. et al. Biodegradation of solid leather wastes. Materie Concianti, [S.1], v. 79, p. 187-195, 2003.

HAROUN, M.; IDRIS, A.; OMAR, S. Analysis of heavy metals during composting of the tannery sludge using physicochemical and spectroscopic techniques. Journal of Hazardous Materials, Amsterdam, v. 165 , p. 111-119, 2009. Disponível em: <http://ac.elscdn.com/S0304389408014271/1-s2.0-S0304389408014271 main.pdf?_tid=86cbdf92-1fcd11e3-987c-00000aacb35d\&acdnat=1379445514_8b92754359ef9ef240e2f073ea206b1b>.

Acesso em: 16 mai. 2013.

KAFLE, B. et al. Anaerobic treatment of apple waste with swine manure for biogas production: Batch and continuous operation. Applied Energy, [S.1.], v.103, p. 61-72, 2013.

KIPPER, E. Tratamento enzimático e produção de biogás por resíduos sólidos de curtume. 2013. 112 f. Dissertação de Mestrado (Programa de Pós-Graduação em Engenharia Química) Universidade Federal do Rio Grande do Sul, Porto Alegre, 2013.

MOLINO A. et al. Biomethane production by anaerobic digestion of organic waste. Fuel, em impressão, 2012. disponível em: <http://dx.doi.org/10.1016/j.fuel.2012.07.070>. Acesso em: 20 mar.2013, 13:30.

PIEROBON, R.L. Sistema de Geração de Energia de Baixo Custo Utilizando Biogás Proveniente de Aterro Sanitário. 2007. 154 f. Tese (Pós Graduação em Engenharia Mecânica) - Universidade Federal do Rio Grande do Sul, Porto Alegre, 2007.

RAPOSO, F. et al. Anaerobic digestion of solid organic substrates in batch mode: An overview relating to methane yields and experimental procedures. Renewable and Sustainable Energy Reviews, [S.1.], v. 16, p. 861-877,2011.

RIAÑO, B. et al. Potential for methane production from anaerobic co-digestion of swine manure with winery wastewater. Bioresource Technology, [S,1.], v.102, p. 4131-4136, 2011.

TAWFIC, A. et al. Factors affecting hydrogen production from rice straw wastes in a mesophillic upflow anaerobic staged reactor. Renewable Energy, [S.1], v.50, p. 402-407, 2013.

THANMAGANI, A. et al Anaerobic co-digestion of hazardous tannery solid waste and primary sludge: biodegradation kinetics and metabolite analysis. Clean Techn Environ Policy, [S.1.], v.12, p. 517-524, 2010. 